\title{
The eyes have it
}

\section{By Sharif Islam, a semi-retired associate in London, UK}

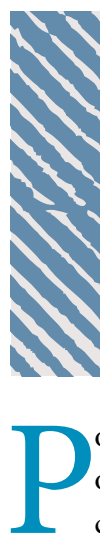

oor little kid. He's only three years old and it's his first time in the dental chair. All the usual inducements aren't working. 'Let's go up in the rocket ship. Do you want to hold the special spoon with the mirror on it? Can you see yourself in the spoon? Are you good at counting? Shall we count how many teeth you have? Who's the good boy that's getting some stickers after he shows me his teeth?'

Yeah, he's not buying it. Because all of it is coming from behind a mask and a visor, and there's only so much emoting these evil eyes can do - even with the furriest eyebrows in the history of our species nestled neatly above them.

If only he could have seen me smiling at him. Perhaps then he wouldn't have burst into a screaming tantrum when I accidentally shredded his cuddly bear while demonstrating the handpiece. Although, granted, the shredding of the bear might have provoked the tantrum regardless.

Now that we continually wear our masks, from the moment we enter the building, our patients are greeted by a voice from a hidden face, spouting the customary pleasantries at them without the accompanying forced look of delight. The patient can remove their mask, of course, unless you plan on performing something other than dentistry, revealing the full spectrum of emotions etched and stretched across their face. Their 害 frustrations and anxieties are slowly decanted to us through their posture, demeanour and tone of voice.

With apparently only $7 \%$ of all communication being verbal, the rest being vocal and visual, it may be time to adapt our $\circlearrowleft$ communication to compensate for the lack door.

of face on display. This is where the acting classes came in handy.

I'm not suggesting for a moment that we all adopt the Stanislavsky method of gesturing and gesticulation, although that could undoubtedly be an entertaining appointment. Nor would I recommend a song and dance audition better suited to a voyeuristic talent show. But everything from our posture to our volume, and even the pace at which we articulate ourselves, can help alleviate our patients' anxiety as much as our gleaming smile when they walk through the

\section{'Everything from our posture to our volume can help alleviate our patients' anxiety'}

Despite the relentless efforts of PPE to hermetically seal us in a sarcophagus of plastic, we still, alas, have to see what we're doing, so our eyes are still visible to everyone. They truly are a window into the soul, assuming you have one, of course; one wouldn't want to be presumptuous. An entire vocabulary of mood and attitude is conveyed by the eyes, so not squinting them in disgust would be a welcome step in the right direction. Unfurrowing one's brow while maintaining eye contact, occasionally punctuated by gentle blinks of acknowledgement and understanding, is another emollient to the inherent tension in the room.
Posture is an obvious tell. I'm sure none of us slouch back on our saddle seats in boredom while the patient regales us with the epic saga of how their toothache spontaneously began while baking a pie. Of course, we lean forward with bated interest, faithful to the adage that if we listen to the patient they will tell us the diagnosis. Or maybe they'll just tell us how tasty the pie was. But the mere demonstration of patience and undiluted attention is a form of communication in itself.

My hands are going on safari a lot more these days. It is, perhaps, an unconscious way of explaining treatments now that I'm reluctantly muzzled like a rabid rottweiler. I try very hard not to poke the patient's eye or jab them in their jowls, but I'm generally successful at making my point. If nothing else, my new Latin dance moves are winning me a lot more attention in COVID-secure nightclubs.

And then there's one's voice. We all know how to feign a soothing tone with a suitably slow and measured delivery. But our elocution matters too, especially with the sound suppression imposed by the masks. I must admit I haven't yet caught up to the modern vernacular of using the 